\title{
Disparities in Cardiovascular Disease and Type 2 Diabetes Risk Factors in Blacks and Whites: Dissecting Racial Paradox of Metabolic Syndrome
}

\author{
Kwame Osei ${ }^{1 *}$ and Trudy Gaillard ${ }^{2}$ \\ ${ }^{1}$ Professor Emeritus of Medicine and Exercise Physiology, Division of Endocrinology, Diabetes and Metabolism, The Ohio \\ State University, Columbus, OH, United States, ${ }^{2}$ College of Nursing, University of Cincinnati, Cincinnati, OH, United States
}

Cardiovascular diseases (CVD) remain as the leading cause of mortality in the western world and have become a major health threat for developing countries. There are several risk factors that account for the CVD and the associated mortality. These include genetics, type 2 diabetes (T2DM), obesity, physical inactivity, hypertension, and abnormal lipids and lipoproteins. The constellation of these risk factors has been termed metabolic syndrome (MetS). MetS varies among racial and ethnic populations. Thus, race and ethnicity account for some of the differences in the MetS and the associated CVD and T2DM. Furthermore, the relationships among traditional metabolic parameters and CVD differ, especially when comparing Black and White populations. In this regard, the

OPEN ACCESS

Edited by:

Jan Polák,

Charles University, Czechia

Reviewed by:

Elisa Danese

University of Verona, Italy

Ludmila Brunerova,

Charles University, Czechia

*Correspondence:

Kwame Osel

kwame.osei@osumc.edu

Specialty section: This article was submitted to Diabetes,

a section of the journal

Frontiers in Endocrinology

Received: 06 June 2017 Accepted: 03 August 2017 Published: 31 August 2017

Citation:

Osei K and Gaillard T (2017) Disparities in Cardiovascular Disease and Type 2 Diabetes Risk Factors in Blacks and Whites: Dissecting Racial Paradox of Metabolic Syndrome.

Front. Endocrinol. 8:204. doi: 10.3389/fendo.2017.00204 greater CVD in Blacks than Whites have been partly attributed to other non-traditional CVD risk factors, such as subclinical inflammation (C-reactive protein), homocysteine, increased low-density lipoprotein oxidation, lipoprotein a, adiponectin, and plasminogen activator inhibitor-1, etc. Thus, to understand CVD and T2DM differences in Blacks and Whites with MetS, it is essential to explore the contributions of both traditional and non-traditional CVD and T2DM risk factors in Blacks of African ancestry and Whites of Europoid ancestry. Therefore, in this mini review, we propose that non-traditional risk factors should be integrated in defining MetS as a predictor of CVD and T2DM in Blacks in the African diaspora in future studies.

Keywords: Blacks, Whites, cardiovascular diseases, type 2 diabetes, lipids/lipoproteins, metabolic syndrome, inflammation

\section{INTRODUCTION}

Metabolic syndrome (MetS) is a constellation of risk factors that predict future cardiovascular disease (CVD) and type 2 diabetes (T2DM) (1-6). MetS affects over 70-80 million Americans in the US and increases with age (2-4). For the past four decades, there has been tremendous debate on the significance of MetS per se when compared to the sum of individual components of MetS. These risk factors include obesity [waist circumference (WC)], blood pressure (BP), fasting triglycerides, high-density lipoprotein cholesterol (HDL-C), and fasting glucose level (1-6). Because of ethnic differences among the MetS components, the International Diabetes Federation (IDF), have provided different guidelines and criteria based on gender, race and ethnicity (7). In this regard, National Cholesterol Education Program-Adult Treatment Panel III (NCEP-ATP) criteria require three or more of the five components to constitute MetS (Table 1). The ATP III does not have race/ethnic based MetS criteria and requires no prerequisite $(1,3,5,8)$. In contrast, the IDF criteria require WC as a prerequisite in addition to two or more parameters for 
the diagnosis of MetS (Table 2). Thus, the prevalence of MetS and its components differ among different racial and ethnic populations (Table 3) (9-14). These metabolic risk factors account in part, for the ethnic differences in cardiovascular mortality and morbidity $(9,12-14)$. Therefore, this mini review will explore further the rationale for the potential disparities in MetS and its outcomes in Blacks of African ancestry and Whites of Europoid origin residing in diverse geographic locations.

\section{PREVALENCE OF MetS IN BLACKS AND WHITES}

Several previous studies have shown that the prevalence of MetS is lower in Blacks when compared to Whites, irrespective of their geographic location (9-14). In fact, the National Health and Nutrition Examination Survey (NHANES III) reported that African-Americans have lower prevalent rates of MetS than Whites in the US (15-21). In particular, African-American males have lower MetS when compared with their White male counterparts (18-21). Recently, the NHANES and other authors have reported higher prevalence of MetS in African-American women $(20,22,23)$. Furthermore, Afro-Caribbean's living in the United Kingdom $(9,14)$ and Blacks in South Africa $(24,25)$ have lower prevalence of MetS than their White counterparts.

TABLE 1 | National cholesterol education program-adult treatment panel III definition of metabolic syndrome (8).

\begin{tabular}{ll}
\hline Components & Criteria \\
\hline Waist circumference & Men $>40$ inches or $>102 \mathrm{~cm}$ \\
& Women $>35$ inches or $>88 \mathrm{~cm}$ \\
Fasting triglycerides & $\geq 150 \mathrm{mg} / \mathrm{dl}$ \\
Blood pressure & $\mathrm{SBP} \geq 130 \mathrm{mmHg}$ and $/$ or DBP $\geq 85 \mathrm{mmHg}$ \\
Fasting glucose & $>100 \mathrm{mg} / \mathrm{dl}$ \\
High-density cholesterol (HDL) & Men $>40 \mathrm{mg} / \mathrm{dl}$ \\
& Women $>50 \mathrm{mg} / \mathrm{dll}$ \\
\hline
\end{tabular}

TABLE 2 | International diabetes federation metabolic syndrome worldwide definition (7).

\begin{tabular}{|c|c|}
\hline Component & Criteria \\
\hline Central obesity & $\begin{array}{l}\text { Waist circumference } \\
\text { Ethnicity specific (Refer to Table 3) }\end{array}$ \\
\hline \multicolumn{2}{|c|}{ Plus any two of the following } \\
\hline Raised triglycerides & $\begin{array}{l}\geq 1.7 \mathrm{mmol} / \mathrm{l}(150 \mathrm{mg} / \mathrm{dl}) \text { or } \\
\text { Specific treatment for this lipid abnormality }\end{array}$ \\
\hline $\begin{array}{l}\text { Reduced high-density } \\
\text { cholesterol }\end{array}$ & $\begin{array}{l}<1.03 \mathrm{mmol} / \mathrm{l}(40 \mathrm{mg} / \mathrm{dl}) \text { in males } \\
<1.29 \mathrm{mmol} / \mathrm{l}(50 \mathrm{mg} / \mathrm{dl}) \text { in females or } \\
\text { Specific treatment for this lipid abnormality }\end{array}$ \\
\hline Raised blood pressure & $\begin{array}{l}\text { Systolic: } \geq 130 \mathrm{mmHg} \text { or } \\
\text { Diastolic: } \geq 85 \mathrm{mmHg} \text { or } \\
\text { Treatment of previously diagnosed hypertension }\end{array}$ \\
\hline $\begin{array}{l}\text { Raised fasting plasma } \\
\text { glucose }\end{array}$ & $\begin{array}{l}\text { Fasting plasma glucose } \geq 5.6 \mathrm{mmol} / \mathrm{l}(100 \mathrm{mg} / \mathrm{dl}) \text { or } \\
\text { previously diagnosed type } 2 \text { diabetes. } \\
\text { If }>5.6 \mathrm{mmol} / \mathrm{l} \text { or } 100 \mathrm{mg} / \mathrm{dl} \text {, oral glucose tolerance } \\
\text { test is strongly recommended but is not necessary to } \\
\text { define presence of the syndrome. }\end{array}$ \\
\hline
\end{tabular}

Paradoxically, despite the lower prevalence of MetS, Blacks suffer disproportionately higher CVD and T2DM and their associated morbidity and mortality than their White counterparts $(12,15$, 17-21, 26). Thus, these metabolic and CVD paradoxes suggest that the processes leading to CVD and T2DM appear to differ in Blacks and Whites.

\section{DISPARITIES IN INSULIN RESISTANCE (IR) IN BLACKS AND WHITES}

The pathophysiology of MetS has been extensively studied for over four decades among racial/ethnic populations by several investigators. The well accepted pathophysiologic lesion underlying MetS is IR/hyperinsulinemia (10-12, 27-32). Whether the IR directly or via the hyperinsulinemia determine MetS remains debatable. Theoretically, insulin plays a critical role in hepatic lipid synthesis, renal sodium reabsorption, arterial tissue growth, and vascular reactivity. These physiologic actions of insulin can partly play a role in the development of clinical obesity, hypertension (HTN), and atherosclerosis by binding to insulin receptor substrate 1 , that stimulates post receptor signaling pathways. Although, these insulin-mediated mechanisms are plausible, direct proof of these concepts remains uncertain in in vivo in humans. Furthermore, there is clear evidence that IR varies among different racial/ethnic populations (10-12, 27-33). In this respect, Blacks (youth and adults) manifest greater IR and insulin levels than their White counterparts $(12,13,24,29,30)$. Factors that contribute to IR include genetics, obesity and lower physical activity, smoking which are higher in Blacks than Whites (27-32). Finally, the relationships of IR and the components of MetS vary among different racial/ethnic populations.

\section{DISPARITIES IN HTN IN BLACKS AND WHITES}

Hypertension is one of the most common non-communicable diseases in the world and it is projected to affect over 1 billion people worldwide $(17,34)$. Thus, BP constitutes a major component of MetS. Consequently, HTN increases the prevalence of

TABLE 3 | Supplement: country/ethnic-specific cutoff points for waist circumference (WC) as described by the international diabetes federation (7).

\begin{tabular}{ll}
\hline Country/ethnic group & WC (as measure of central obesity) \\
\hline Europoids & Male $\geq 94 \mathrm{~cm}$ \\
& Female $\geq 80 \mathrm{~cm}$ \\
South Asians & Male $\geq 90 \mathrm{~cm}$ \\
& Female $\geq 80 \mathrm{~cm}$ \\
Chinese & Male $\geq 90 \mathrm{~cm}$ \\
& Female $\geq 80 \mathrm{~cm}$ \\
Japanese & Male $\geq 85 \mathrm{~cm}$ \\
& Female $\geq 80 \mathrm{~cm}$ \\
Ethnic South and Central & Use South Asian recommendations until more \\
Americans & specific data are available \\
Sub-Saharan Africans & Use European data until more specific data \\
& are available \\
Eastern Mediterranean and & Use European data until more specific data are \\
Middle East & available (Arab) populations
\end{tabular}


CVD outcomes, such as stroke, congestive heart failure, kidney failure and cognitive impairment/dementia in both developed and underdeveloped countries among racial and ethnic populations (17). In this regard, Blacks are more disproportionately affected by HTN and its comorbid conditions. In the US, the prevalence of $\mathrm{HTN}$ is $40-50 \%$ in African-Americans when compared to $25-30 \%$ in Whites $(35,36)$. Furthermore, the prevalence of HTN associated complications are higher in Blacks than Whites. Compared to Whites, Blacks have higher prevalence of heart failure, by twofold, stroke, by twofold to fourfold and kidney failure, by twofold to fourfold in the US (11-13, 34-36). These could partly explain the higher disparities in CVD outcomes in Blacks than Whites. Although, most patients have essential HTN, some authorities believe IR might be the underpinning lesion of MetS, especially regarding BP $(10,11,34-36)$. However, the mechanism(s) by which IR causes higher BP remains debatable. Indeed, while IR correlates with BP in Whites, this is not the case in Blacks. The reasons for the IR and BP paradox in Blacks remain uncertain.

\section{DISPARITIES IN GLUCOSE TOLERANCE AND T2DM IN BLACKS AND WHITES}

Diabetes has become a global epidemic, especially in minority populations. The prevalence of glucose intolerance, prediabetes and T2DM is higher in Blacks than Whites who reside in diverse geographic locations $(5,16,17,26,30,37,38)$. There is a growing evidence for epidemic of T2DM in minority populations (39). In this context, it is estimated that the prevalence of T2DM is $1.5-2 \times$ higher in Blacks than Whites in the US (37). Furthermore, these racial differences in T2DM have been observed in Blacks residing in United Kingdom $(6,10,14,26,40)$ and South Africa $(6,24,25)$. The reasons for the racial disparity in diabetes in Blacks and Whites are unknown, but appear to be multifactorial including genetic inheritance and environment factors (physical inactivity, nutrition, obesity, lower socioeconomic status, smoking, etc.).

Pathogenically, glucose intolerance and T2DM have been attributed to alterations in beta cell function, decreased insulin secretion and IR (both peripheral and hepatic) (27-33). Blacks residing in the western world are more hyperinsulinemic and manifest greater IR than their White counterparts, independent of obesity $(10,11,29,31-33)$. The higher insulin responses to glucose and non-glucose stimulation in non-diabetic Blacks can be attributed to greater beta cell secretion and defective hepatic extraction or insulin clearance (31-33). Although, the molecular mechanism for the altered beta cell secretion and insulin kinetics and IR remain uncertain in patients with T2DM, there is a clear evidence for genetic (and epigenetic) as well as environmental factors such as physical inactivity and overweight/obesity which are higher in Blacks and Whites.

\section{DISPARITIES IN LIPIDS AND LIPOPROTEINS IN BLACKS AND WHITES}

Alterations in lipids and lipoproteins that play pathogenic role in atherosclerosis are major components of MetS (1-3). Typically, the MetS is associated with higher serum triglycerides and lower HDL-C and higher small dense low-density lipoprotein (LDL) (apo B) particles $(1,41-48)$. This has been attributed in part to the underlying IR and obesity (1-5, 31-33). These abnormalities exist in patients with prediabetes and progresses with time (48). However, the relationships between IR and lipids and lipoproteins differ among racial and ethnic populations (49-55). In this regard, IR is associated with lower triglycerides and higher HDL-C in Blacks than Whites $(29-33,51,52)$. Thus, these relationships are inverse and paradoxical in Blacks with MetS than Whites residing in diverse geographic locations. Therefore, it has been postulated that, compared to Whites, Blacks with and without MetS have favorable anti-atherogenic lipid and lipoprotein profiles that could theoretically protect them against CVD, but this is not the case. Therefore, fasting triglycerides and trig/HDL-C ratios appear not to be markers of IR in Blacks $(29-33,51,52)$. The reasons for this metabolic paradox remain unknown. We $(22,31-33,48)$ and others $(27,46,47,51)$ have attributed the lower triglycerides in Blacks than Whites to possible defective hepatic synthesis of very low-density lipoprotein (VLDL) as measured by particle concentrations, numbers and sizes derived from Nuclear Magnetic Resonance (NMR) spectroscopy (41-48). In this regard, the proposed underlying defect has been attributed in part to hepatic lipase gene mutation (45-47). In addition Mijkoviv-Gacic et al. (46) and Frazier-Wodds et al. (47) reported lower NMR-derived total, medium, and small VLDL particles in African-Americans and Afro-Caribbeans when compared to Whites. Hence, it can be inferred that the racial and ethnic differences in lipids and lipoprotein profile cannot explain the paradoxically higher and excess CVD mortality and morbidity in Blacks when compared to Whites (17-20). Answers to these questions deserve further elucidation. In support of this concept, the number of large HDL particles are greater in non-diabetic Blacks than Whites (46-48). Furthermore, using NMR-derived lipoprotein, LDL particle sizes and numbers are consistent with the well accepted pathogenic role in atherosclerosis in Whites, but not so for Blacks (46-48). In fact, Blacks have large LDL particles, which are more buoyant and less atherogenic than Whites. These findings are consistent with those from the Dallas Heart Study (45) and Multi-Ethnic Study of Atherosclerosis $(44,54)$.

\section{DISPARITIES IN OVERWEIGHT/OBESITY IN BLACKS AND WHITES}

Obesity has become epidemic globally especially in minority populations $(1,5,6,15,16,24,33,38,40)$. This is particularly so for Blacks of African ancestry residing in urban and inner cities of the western world when compared with their White counterparts $(11,24,55-62)$ and Blacks residing in rural areas in Africa $(6,14,40,55-57,59)$. In fact, the prevalence of overweight and obesity approaches $70 \%$ in Blacks when compared to $50 \%$ in Whites in the US $(5,20)$. The obesity with the associated IR accounts partly for the myriads of diseases such as CVD, T2DM, HTN, obstructive sleep disorder, CHF, stroke and cancer. In this context, obesity with the truncal obesity (WC) is regarded as a pivotal clinical indicator of MetS $(5-7,55,56,63,64)$. However, 
the biological significance of WC varies and remains debatable among racial and ethnic populations $(7,55,56,63,64)$. Specifically, the regional body fat distribution and composition tend to vary among ethnic and racial populations. For example, for identical body mass index, Blacks have lower intra-abdominal visceral adiposity (VAT) when compared to Whites $(63,64)$. Moreover, the corresponding subcutaneous fat depot (SAT) tends to be the same or greater in Blacks than Whites in both genders $(63,64)$. The reasons for the racial and ethnic disparities in VAT and SAT distribution remain uncertain and debatable.

The metabolic consequences of obesity/overweight have been attributed to the biological activity of the adipocytes and adipose tissues unique to the fat distribution such as visceral and subcutaneous adiposity or fat deposition. In particular, intra-abdominal VAT in general is more biologically active and it is associated with systemic and hepatic IR in several non-Black populations (57). However, despite the greater IR in Blacks, the corresponding VAT is lower in Blacks than Whites $(63,64)$. The reasons and the mechanisms of the VAT and IR paradox in Blacks remain unknown and debatable.

\section{DISPARITIES IN LIPID OXIDATION AND SUBCLINICAL INFLAMMATION IN BLACKS AND WHITES}

Recently, there has been increasing interest in the role of nontraditional markers in CVD and T2DM which also underpin MetS. In this context, lipid oxidation is an important etiologic factor in CVD and T2DM. In particular, oxidized LDL serves as the foundation or causative factor for vascular endothelial injury and the development of fatty streak or plaque and early atherogenesis $(65,66)$. The oxidative processes are mediated through changes in super-oxide dismutase or free oxygen radicals $(67,68)$. Clinically, these processes can be assessed as oxidized LDL and $\mathrm{F}_{2}$ Isoprostanes. This concept suggests that reducing LDL oxidation could also potentially reduce CVD and T2DM. In this regard, to minimize or reduce LDL oxidation, HDL has been implicated as a potent antioxidant agent especially against LDL particle oxidation (69-72). Furthermore, HDL is regarded as anti-inflammatory particle with anti-vascular injury properties $(71,72)$.

Previous studies have demonstrated that HDL is a potent antiatherogenic particle. In addition, Apo AII, thelargest HDL protein, has been postulated to play a major role as anti-atherogenic. In this context, both Apo AII and HDL-C levels are higher in Blacks than Whites with and without T2DM and MetS (41, 42, 52-54). But these higher HDL particles do not appear to protect against CVD in Blacks when compared to Whites (13-18). The reasons are unknown. Another potential mechanism for HDL oxidation is paraoxonase. In this context, we should note that, some of the anti-atherogenic biological properties of HDL have also been partly attributed to paraoxonase enzyme 1 (PON1), a major component of HDL (66-70). PON1 which cosegregates with HDL in the circulation is partly responsible for the antioxidant (oxidized LDL) and anti-inflammatory properties [C-reactive protein (CRP)] of HDL (66-69). In this regard, oxidized LDL level and CRP are 50\% higher in Blacks when compared to
Whites (69). It should be noted that subclinical inflammation is considered as an important etiologic factor for both CVD and T2DM. In this context, CRP levels which are indicators of subclinical inflammation are significantly elevated in Blacks than Whites who have increased propensity for CVD, T2DM and MetS $(65-69,73)$. These findings indicate that the higher HDL levels appear to be dysfunctional in Blacks compared to Whites (69). In support of the HDL dysfunctionality concept, Blacks have greater large HDL particles than Whites (44-46). Similar to the concept of HDL dysfunctionality in Blacks, Dodani et al. (70) demonstrated that HDL function is lower or impaired in South Asian Indians, a population with extreme propensity for CVD and its outcomes, when compared to Whites.

\section{DISPARITIES IN ADIPOCYTOKINES AND OTHER NON-TRADITIONAL RISK FACTORS IN BLACKS AND WHITES}

Non-traditional CVD markers include aipocytokines such as adiponectin, interleukin 6 (IL-6), tumor necrosis factor alpha, homocysteine plasminogen activator inhibitor-1 (PAI-1), as well as platelate aggregration factor, etc., which are mostly derived from adipocytes (74-82). Physiologically, adiponectin, 244 aa protein which is solely derived from adipocytes, is a potent endogenous insulin sensitizer (peripheral and hepatic) and tends to increase with weight loss (physical exercise, bariatric surgery, etc.) and use of some drugs such as thiazolidinediones. However, the circulating levels of adiponectin vary according to race and ethnicity. In this regard, Blacks with and without T2DM, who are normal weight, overweight or obese, have lower adiponectin levels when compared to their White counterparts (74-77). Thus, the role of adiponectin in CVD and T2DM warrants further investigation. Whether the adiponectin synthesis is lower or its clearance is higher in Blacks compared to Whites remain to be elucidated.

There are other non-traditional CVD and Type 2 DM risk factors. We propose that these non-traditional risk factors play critical role in CVD and its outcomes in African-Americans than Whites $(81,82)$. These other non-traditional risk factors in the development of CVD include alterations in homocysteine, PAI-1, Lp (a) as well as platelet aggregation factors and hypercoagulability. However, whether normalization of disparities in these non-traditional risk factors can provide additional benefits in CVD outcomes in Blacks than Whites with MetS deserves further elucidation.

In summary, there is a strong and convincing evidence to support ethnic and racial difference in MetS and its components in Blacks when compared to Whites. However, these metabolic disparities in Blacks cannot explain the excess CVD and T2DM than in Whites. These issues are particularly relevant when using traditional metabolic risk factors rather than non-traditional biomarkers (Figure 1). Thus, it is important to incorporate or include non-traditional markers, such as CRP, IL-6, adipocytokines, oxidized LDL, homocysteine, PAI-1, platelet aggregation factor, etc., in assessing the risk for CVD and T2DM in Blacks of African Ancestry who reside in diverse geographic locations (Figure 1). 


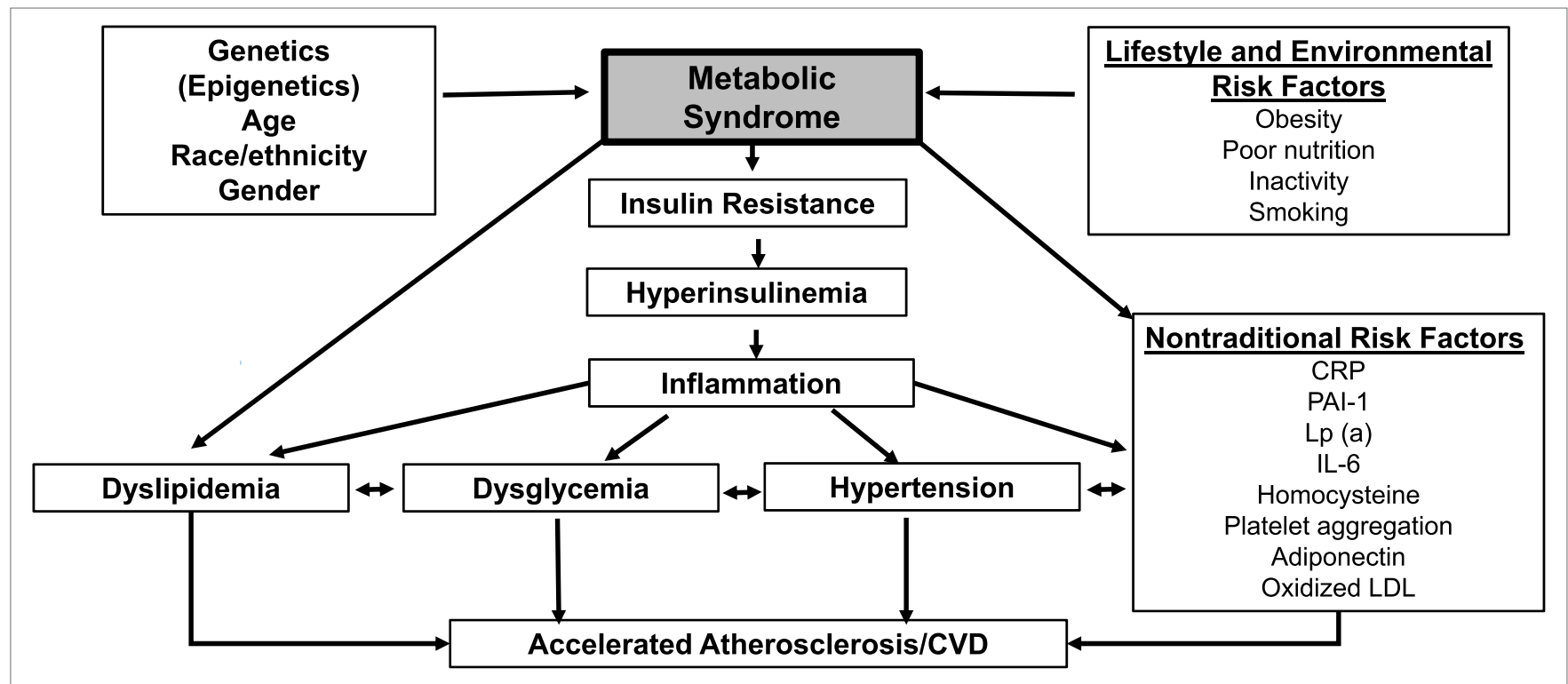

FIGURE 1 | Schematic diagram of metabolic syndrome (MetS) and its contributory factors. Legend: schematic diagram of MetS and its contributory factors. C-reactive protein (CRP), plasminogen activator inhibitor-1(PAI-1), lipoprotein a [Lp (a)], interleukin 6 (IL-6), low-density lipoprotein (LDL).

\section{CONCLUSION}

Racial and ethnic disparities in CVD and T2DM risk factors exist in Blacks and Whites with MetS residing in geographic locations. Although, the exact reasons are unknown, emerging evidence support genetic as well as environmental factors in the development of CVD and T2DM. Thus, further research to investigate the genetic markers and metabolic and body fat compositional parameters as well as non-traditional risk factors are needed to develop novel new definition and criteria for

\section{REFERENCES}

1. Grundy SM, Hansen B, Smith SC Jr, Cleeman JI, Kahn RA, American Heart Association, et al. Clinical management of metabolic syndrome: report of the American Heart Association/National Heart, Lung, and Blood Institute/ American Diabetes Association conference on scientific issues related to management. Circulation (2004) 109:551-6. doi:10.1161/01.CIR.0000112379. 88385.67

2. Sattar N, Mc Connachie A, Shaper AG, Blauw GJ, Buckley BM, de Craen AJ, et al. Can metabolic syndrome usefully predict cardiovascular disease and diabetes? Outcome data from two prospective studies. Lancet (2008) 371:1927. doi:10.1016/S0140-6736(08)60602-9

3. McNeill A, Rosemond W, Girman C, Golden SH, Schmidt MI, East HE, et al. The metabolic syndrome and 11-year risk of incident cardiovascular disease in the Atherosclerosis Risk in Communities Study. Diabetes Care (2005) 28:385-90. doi:10.2337/diacare.28.2.385

4. Galassi A, Reynolds K, He J. Metabolic syndrome and risk of cardiovascular disease: a meta-analysis. Am J Med (2006) 119:812. doi:10.1016/j.amjmed. 2006.02.031

5. Meigs JB, Wilson PW, Fox CS, Vasan RS, Nathan DM, Sullivan LM, et al. Body mass index, metabolic syndrome, and risk of type 2 diabetes or cardiovascular disease. J Clin Endocrinol Metab (2006) 91:2906. doi:10.1210/jc.2006-0594

6. Kelliny C, Williams J, Riesen W, Paccaud F, Bovert P. Metabolic syndrome according to different definitions in a rapidly developing country of the African region. Cardiovasc Diabetol (2008) 18(7):27. doi:10.1186/1475-2840-7-27
MetS that can predict CVD and T2DM in Blacks and Whites residing in diverse geographic locations. We believe this could provide more effective prevention and treatment of CVD and T2DM among Blacks residing in diverse geograhic locations.

\section{AUTHOR CONTRIBUTIONS}

Both authors have contributed to the manuscript, the literature review, analysis, interpretation and editing for the final submission.

7. Alberti K, Zimmet P, Shaw J. Metabolic syndrome - a new world-wide definition. A consensus statement from the International Diabetes Federation. Diabet Med (2006) 23:469-80.

8. Expert Panel on Detection, Evaluation, and Treatment of High Blood Cholesterol in Adults. Executive summary of the Third Report of the National CholesterolEducation Program(NCEP) ExpertPanelon Detection, Evaluation, and Treatment of High Blood Cholesterol in Adults (Adult Treatment Panel III). JAMA (2001) 285:2486-97. doi:10.1001/jama.285.19.2486

9. Tillin T, Foeouhi N, Johnson D, McKeigur P, Chaturvedi N, Godsland IF. Metabolic Syndrome and coronary heart disease in South Asians, AfricanCaribbeans and White Europeans: a UK population-based cross-sectional study. Diabetologia (2005) 48:649-56. doi:10.1007/s00125-005-1689-3

10. Kalk W, Joffe B. The metabolic syndrome, insulin resistance and its surrogates in African and White subjects with type 2 diabetes in South Africa. Metab Syndr Relat Disord (2008) 6:247-55. doi:10.1089/met.2008.0003

11. Lteif A, Han K, Mather K. Obesity, insulin resistance, and the metabolic syndrome: determinants of endothelial dysfunction in Whites and Blacks. Circulation (2005) 112:32-8. doi:10.1161/CIRCULATIONAHA.104.520130

12. Hutchinson RG, Watson RL, Davis CE, Barnes R, Brown S, Romm F, et al Racial differences in risk factors for atherosclerosis. The ARIC study: Atherosclerosis Risk in Communities. Angiology (1997) 48:279-90. doi:10.1177/000331979704800401

13. Tzou WS, Douglas PS, Srinivasan SR. Increased subclinical atherosclerosis in young adults with metabolic syndrome. The Bogalusa Heart Study. J Am Coll Cardiaol (2005) 46:457-63. doi:10.1016/j.jacc.2005.04.046 
14. Kalra L, Iveston E, Rambaran C, Sherwood R, Chowienczyk P, Ritter J, et al. An international matched cohort study of the contribution of metabolic impairments to subclinical atherosclerosis in United Kingdom and Jamaican African-Caribbeans. Atherosclerosis (2008) 199:95-101. doi:10.1016/j. atherosclerosis.2007.10.013

15. Carnethon MR, Loria CM, Hill JO, Sidney S, Savage PJ, Liu KL, et al. Risk factors for the metabolic syndrome: the Coronary Artery Risk Development in Young Adults (CARDIA) Study, 1985-2001. Diabetes Care (2004) 27(11):2707-15. doi:10.2337/diacare.27.11.2707

16. Meis SB, Schuster D, Gaillard T, Osei K. Metabolic syndrome in non-diabetic, obese first degree relatives of African American patients with type 2 diabetes. African American triglycerides-HDL-C and insulin resistance paradox. Ethn Dis (2006) 16:830-6.

17. Okosun IS, Annor F, Dawodu EA, Eriksen MP. Clustering of cardiometabolic risk factors and risk of elevated HbAlc in non-Hispanic White, non-Hispanic Black and Mexican-American adults with type 2 diabetes. Diabetes Metab Syndr (2014) 8(2):75-81. doi:10.1016/j.dsx.2014.04.026

18. Ford ES, Giles WH, Mokdad AH. Increasing prevalence of the metabolic syndrome among US Adults. Diabetes Care (2004) 27:2444-9. doi:10.2337/ diacare.27.10.2444

19. Park Y-W, Zhu S, Palaniappan L, Heshka S, Carnethon MR, Heymsfield SB. The metabolic syndrome: prevalence and associated risk factor findings in the US population from the Third National Health and Nutrition Survey. 1988-1994. Arch Intern Med (2003) 24:427-62. doi:10.1001/archinte.163.4.427

20. Ford E, Giles W, Dietz W. Prevalence of the metabolic syndrome among US Adults. Findings from the Third National Health and Nutrition Examination Survey. JAMA (2002) 287:356-9. doi:10.1001/jama.287.3.356

21. Palaniappan L, Carnethon M, Wang Y, Hanley A, Forthmann S, Haffner S, et al. Predictors of the incident Metabolic Syndrome in Adults. Diabetes Care (2004) 27:788-93. doi:10.2337/diacare.27.3.788

22. Gaillard T, Schuster D, Osei K. Independent role of blood pressure on cardiovascular risk factors in nondiabetic, obese African American Women: implications for metabolic syndrome thresholds. J Am Soc Hypertens (2009) 3:25-34. doi:10.1016/j.jash.2008.07.003

23. Appel SJ, Oster RA, Floyd NA, Ovalle F. Cardiometabolic risk among African American women: a pilot study. J Cardiovasc Nurs (2009) 24(2):140-50. doi:10.1097/JCN.0b013e318197aa3a

24. Jennings CI, Lambert EV, Collins M, Levitt NS, Goedecke JH. The atypical presentation of the metabolic syndrome components in Black African women: the relationship with insulin resistance and the influence of regional adipose tissue distribution. Metabolism (2009) 58:149-57. doi:10.1016/j. metabol.2008.09.007

25. Schutte AE, Olckers A. Metabolic syndrome risk in Black South African women. Horm Metab Res (2007) 39(9):651-7. doi:10.1055/s-2007-985394

26. Strain W, Chaturvedi N, Nihoyannopoulos P, Bulpitt C, Rajkumar C, Shore A. Differences in the association between type 2 diabetes and impaired microvascular function among Europeans and African Caribbeans. Diabetologia (2005) 48:2269-77. doi:10.1007/s00125-005-1950-9

27. Haffner SM, D’Agostino R Jr, Saad MF, Rewers M, Mykkanen L, Shelby J, et al. Increased insulin resistance and insulin secretion in nondiabetic AfricanAmericans and Hispanics compared with non-Hispanic Whites. The Insulin Resistance Atherosclerosis Study. Diabetes (1996) 45:742-7.

28. Ferrannini E, Mari A. Beta cell function and its relation to insulin action in humans: a critical appraisal. Diabetologia (2004) 47:943-56. doi:10.1007/ s00125-004-1381-z

29. Lorenzo C, Wagenknecht LE, D'Agostino RB, Rewers MJ, Karter AJ, Haffner SM. Insulin resistance, $\beta$-cell dysfunction, and conversion to type 2 diabetes in a multiethnic population: the Insulin Resistance Atherosclerosis Study. Diabetes Care (2010) 33:67-72. doi:10.2337/dc09-1115

30. Haffner SM, Howard G, Mayer E, Bergman RN, Savage PJ, Rewers M, et al. Insulin sensitivity and acute insulin responses in African Americans, non-Hispanic Whites and Hispanics and NIDDM: the Insulin Resistance and Atherosclerosis Study. Diabetes (1997) 46:63-9. doi:10.2337/diabetes.46.1.63

31. Osei K, Cottrell DA. Minimal model analyses of insulin-sensitivity and glucose-dependent glucose disposal in Black and White Americans. Eur J Clin Invest (1994) 24:843-50. doi:10.1111/j.1365-2362.1994.tb02029.x

32. Osei K, Schuster D. Ethnic differences in secretion, sensitivity and hepatic extraction of insulin in Black and White Americans. Diabet Med (1994) 11:755-62. doi:10.1111/j.1464-5491.1994.tb00349.x
33. Harris MI, Cowie CC, Gu K, Francis ME, Flegal K, Eberhardt MS. Higher fasting insulin but lower fasting C-peptide levels in African Americans in the US population. Diabetes Metab Res Rev (2002) 18:149-55. doi:10.1002/ dmrr.273

34. Gu Q, Burt V, Paulose-Ram R, Yoon S, Gillium R. High blood pressure and cardiovascular disease mortality risk among U.S. adults: the third National Health and Nutrition Examination Survey mortality follow-up study. Ann Epidemiol (2008) 18:302-9. doi:10.1016/j.annepidem.2007.11.013

35. Centers for Disease Control and Prevention, National Center for Health Statistics. Underlying Cause of Death 1999-2013 on CDC WONDER Online Database, Released 2015. Data Are from the Multiple Cause of Death Files, 19992013, as Compiled from Data Provided by the 57 Vital Statistics Jurisdictions through the Vital Statistics Cooperative Program. (2017). Available from: http:// wonder.cdc.gov/ucd-icd10.html

36. Nwankwo T, Yoon SS, Burt V, Gu Q. Hypertension among Adults in the US: National Health and Nutrition Examination Survey, 2011-2012. NCHS Data Brief, No. 133. Hyattsville, MD: National Center for Health Statistics, Centers for Disease Control and Prevention, US Dept of Health and Human Services (2013).

37. Gillum R, Mussolino M, Madans J. Diabetes Mellitus, coronary heart disease incidence, and death from all cause in African American and European American women. The NHANES I Epidemiologic Follow-up Study. J Clin Epidemiol (2000) 53:511-8. doi:10.1016/S0895-4356(99)00208-5

38. McLaughlin T, Abbasi F, Lamendola C, Reaven G. Heterogeneity in the prevalence of risk factors for cardiovascular disease and type 2 diabetes mellitus in obese individuals: effect of differences in insulin sensitivity. Arch Intern Med (2007) 167:642. doi:10.1001/archinte.167.7.642

39. IDF Diabetes Atlas. 7th ed. (2015). Available from: www.diabetesatlas.org

40. Agyemang C, Meeks K, Beune E, Owusu-Dabo E, Mockenhaupt FP, Addo J, et al. Obesity and type 2 diabetes in sub-Saharan Africans - is the burden in today's Africa similar to African immigrants in Europe? The RODAM study. BMC Med (2016) 14(1):166. doi:10.1186/s12916-016-0709-0

41. Vora AN, Ouyang P, Bittner V, Tardif JC, Waters DD, Vaidya D. Racial differences of lipoprotein subclass distributions in postmenopausal women. Ethn Dis (2008) 18(2):176-80.

42. Mora S, Glynn RJ, Ridker PM. High-density lipoprotein cholesterol, size, particle number, and residual vascular risk after potent statin therapy. Circulation (2013) 128(11):1189-97. doi:10.1161/CIRCULATIONAHA.113.002671

43. Burns SF, Lee S, Arslanian SA. In vivo insulin sensitivity and lipoprotein particle size and concentration in Black and White children. Diabetes Care (2009) 32(11):2087-93. doi:10.2337/dc09-0380

44. Mora S, Sziklo M, Otvos JD, Greenland P, Psaty BM, Goff DC Jr, et al. LDL particle subclasses, LDL particle size and carotid atherosclerosis in the MultiEthnic Study of Atherosclerosis (MESA). Atherosclerosis (2007) 192(9):211-7. doi:10.1016/j.atherosclerosis.2006.05.007

45. Chandra A, Neeland IJ, Das SR, Khera A, Turer AT, Ayers CR, et al. Relation of Black Race between high density lipoprotein cholesterol content, high density lipoprotein particles and coronary events (from the Dallas Heart Study). Am J Cardiol (2015) 115(7):890-4. doi:10.1016/j.amjcard.2015.01.015

46. Mijkovic-Gacic IV, Bunker CH, Ferrrel RE, Kammer CM, Evans RW, Paatrick AL, et al. Lipoprotein subclass and particle size differences in AfroCaribbeans, African Americans and White Americans: association with hepatic lipase gene variation. Metabolism (2006) 55(1):96-102. doi:10.1016/j. metabol.2005.07.011

47. Frazier-Woods AC, Manichaikaul A, Boreck IB, Goff DC, Hopkins PN, Lai $\mathrm{CQ}$, et al. Genetic variants associated with VLDL, LDL, and HDL particle size differ by race and ethnicity. Hum Genet (2013) 132:405-13. doi:10.1007/ s00439-012-1256-1

48. Gaillard T, Osei K. Ethnic differences in lipids and lipoproteins in overweight/obese African American and White American women with prediabetes: significance of NMR-derived lipoprotein particle concentrations and sizes. BMJ Open Diab Res Care (2016) 4(1):e000246. doi:10.1136/ bmjdrc-2016-000246

49. Cowie CC, Howard BV, Harris MI. Serum lipoproteins in African Americans and Whites with noninsulin-dependent diabetes in the U.S. population. Circulation (1991) 90:1185-91. doi:10.1161/01.CIR.90.3.1185

50. Li C, Ford E, Meng Y, Mokdad A, Reaven G. Does the association of the triglyceride to high-density lipoprotein cholesterol ratio with fasting serum insulin differ by race/ethnicity? Cardiovasc Diabetol (2008) 7(4):1-9. doi:10.1186/1475-2840-7-4 
51. Sumner A, Vega G, Genovese D, Finley K, Bergman R, Boston R. Normal triglyceride levels despite insulin resistance in African Americans: role of lipoprotein lipase. Metabolism (2005) 54:902-9. doi:10.1016/j.metabol.2005.03.001

52. Sumner AE, Finley KB, Genovese DJ, Criqui MH, Boston RC. Fasting triglycerides and the triglyceride-HDL-Cholesterol ratio are not markers of insulin resistance in African Americans. Arch Intern Med (2005) 165:1395-400. doi:10.1001/archinte.165.12.1395

53. Zoratti R. A review on ethnic difference in plasma triglycerides and high density lipoprotein cholesterol: is the lipid pattern the key factor for the low coronary heart disease rates in people of African origins? Eur J Epidemiol (1998) 14:9-21. doi:10.1023/A:1007492202045

54. Mackey RH, Greenland P, Goff DC, Lloyd-Jones CT, Sibley D, Mora S. Highdensity lipoprotein cholesterol and particle concentrations, carotid atherosclerosis, and coronary events: MESA (Multi-Ethnic Study of Atherosclerosis). J Am Coll Cardiol (2012) 60(6):508-16. doi:10.1016/j.jacc.2012.03.060

55. Fezeu L, Balkau B, Kenane A, Sobngwi E, Mbanya J. Metabolic syndrome in a sub-Saharan African setting: central obesity may be the key determinant. Atherosclerosis (2007) 193:70-6. doi:10.1016/j.atherosclerosis.2006.08.037

56. Jennings CL, Lambert EV, Collins M, Joffe Y, Levitt NA, Groedecke JH. Determinants of insulin -resistant phenotypes in normal weight and obese Black African Women. Obesity (2008) 10:1-8.

57. Crowther NJ, Ferris WF, Ojwang PPJ, Rheeder P. The effect of abdominal obesity on insulin sensitivity and serum lipid and cytokine concentrations in African women. Clin Endocrinol (2006) 64:535-41. doi:10.1111/j.1365-2265. 2006.02505.x

58. Zhu S, Heymsfield S, Toyoshima H, Wang Z, Pietrobelli A, Heshka S. Raceethnicity-specific waist circumference cutoffs for identifying cardiovascular disease risk factors. Am J Clin Nutr (2005) 81(2):409-15.

59. Amoah AG. Oseisty in adult residents of Accra, Ghana. Ethn Dis (2003) 13(Suppl 2):S97-101.

60. Taylor H, Liu J, Wilson G, Golden S, Crook E, Brunson C, et al. Distinct component profiles and high risk among African Americans with the metabolic syndrome: the Jackson Heart Study. Diabetes Care (2008) 31:1248-52. doi: $10.2337 / \mathrm{dc} 07-1810$

61. Mokdad A, Bowman B, Ford E, Vinicor F, Marks J, Koplan J. The continuing epidemics of obesity and diabetes in the United States. JAMA (2001) 286:1195-200. doi:10.1001/jama.286.10.1195

62. St-Ong M, Jassen I, Heymsfield S. Metabolic syndrome in normal-weight Americans: new definition of the metabolically obese, normal-weight individual. Diabetes Care (2004) 27:2222-8. doi:10.2337/diacare.27.9.2222

63. Lovejoy JC, Bretonne JA, Klemperer M, Tulley R. Abdominal fat distribution and metabolic risk factors: effects of race. Metabolism (1996) 45:1119-24. doi:10.1016/S0026-0495(96)90011-6

64. Albu J, Murphy L, Frager D, Johnson J, Pi-Sunyer F. Visceral fat and race dependant health risk factors. Effect of race. Metabolism (1996) 45:1119-24. doi:10.1016/S0026-0495(96)90011-6

65. Parthasarathy S, Barnett J, Fong LG. High-density lipoprotein inhibits the oxidative modification of low-density lipoprotein. Biochim Biophys Acta (1990) 1044(2):275-83. doi:10.1016/0005-2760(90)90314-N

66. Mackness MI, Arrol S, Abbott C, Durrington PN. Protection of low-density lipoprotein against oxidative modification by high-density lipoprotein associated paraoxonase. Atherosclerosis (1993) 104(1-2):129-35. doi:10.1016/00219150(93)90183-U

67. Rosenblat M, Karry R, Aviram M. Paraoxonase 1 (PON1) is a more potent antioxidant and stimulant of macrophage cholesterol efflux, when present in HDL than in lipoprotein-deficient serum: relevance to diabetes. Atherosclerosis (2006) 187(1):74-81. doi:10.1016/j.atherosclerosis.2005.08.026

68. Aviram M, Rosenblat M, Bisgaier CL, Newton RS, Primo-Parmo SL, La Du BN. Paraoxonase inhibits high-density lipoprotein oxidation and preserves its functions. A possible peroxidative role for paraoxonase. J Clin Invest (1998) 101(8):1581-90. doi:10.1172/JCI1649

69. Gaillard T, Parthasarathy S, Osei K. HDL dysfunctionality (paraoxonase) is worse in nondiabetic, postmenopausal African American than in White women. Diabetes Care (2011) 34(2):e19-1189. doi:10.2337/dc10-1189
70. Dodani S, Kaur R, Redy S, Reed GL, Navab M, George V. Can dysfunctional HDL explain high coronary artery disease risk in South Asians? Int J Cardiol (2008) 129(1):125-32. doi:10.1016/j.ijcard.2007.12.019

71. Zeiher AM, Schachlinger V, Hohnloser SH, Saurbier B, Just H. Coronary atherosclerotic wall thickening and vascular reactivity in humans. Elevated high-density lipoprotein levels ameliorate abnormal vasoconstriction in early atherosclerosis. Circulation (1994) 89(6):2525-32. doi:10.1161/01. CIR.89.6.2525

72. Sugano M, Tsuchida K, Makino N. High-density lipoproteins protect endothelial cells from tumor necrosis factor-alpha-induced apoptosis. Biochem Biophys Res Commun (2000) 272(3):872-6. doi:10.1006/bbrc.2000.2877

73. Ridker PM, Danielson E, Fonseca FA, Genest J, Gotto AM Jr, Kastelein JJ, et al. Rosuvastatin to prevent vascular events in men and women with elevated C-reactive protein. N Engl J Med (2008) 359:2195-207. doi:10.1056/ NEJMoa0807646

74. Ferris WF, Naran NH, Crowther NJ, Rheeder P, Van der Merwe L, Cherry N. The relationship between insulin sensitivity and serum adiponectin levels in three population groups. Horm Metab Res (2005) 11:695-701. doi:10.1055/s2005-870580

75. Hulver MW, Saleh O, MacDonald KG, Poeries WJ, Barakat HA. Ethnic differences in adiponectin levels. Metabolism (2004) 53:1-5. doi:10.1016/j. metabol.2003.07.002

76. Duncan BB, Schmidt MI, Pankow JS, Bang H, Copper D, Baiantyne CH, et al. Adiponectin and the development of type 2 diabetes. The Atherosclerosis Risk in Communities Study. Diabetes (2004) 53:2473-8. doi:10.2337/ diabetes.53.9.2473

77. Osei K, Scott R, Gaillard T, Schuster D. Plasma adiponectin in first degree relatives of African Americans parents with type 2 diabetes with normal glucose tolerance, impaired glucose tolerance and type 2 diabetes. Obes Res (2005) 13:179-85. doi:10.1038/oby.2005.23

78. Edelstein LC, Simon LM, Montoya RT, Holinstat M, Chen ES, Bergeron A, et al. Racial difference in human platelet PAR4 reactivity reflects expression of PCTP and miR-376c. Nat Med (2013) 19(12):1609-16. doi:10.1038/ nm. 3385

79. Berlin I, Lin S, Lima JAC, Gerald Bertoni AG. Smoking status and metabolic syndrome in the Multi-Ethnic Study of Atherosclerosis. A cross-sectional study. Tob Induc Dis (2012) 10:9. doi:10.1186/1617-9625-10-9

80. Albert MA, Glynn RJ, Buring J, Ridker PM. C-Reactive protein levels among women of various ethnic groups living in the United States (from the Women's Health Study). Am J Cardiol (2004) 93:1238-42. doi:10.1016/j. amjcard.2004.01.067

81. Cao J, Steffen BT, Budoff M, Post WS, Thanassoulin G, Kestenbaum B, et al. Lipoprotein(a) levels are associated with subclinical calcific aortic valve disease in White and Black individuals: the Multi-Ethnic Study of Atherosclerosis. Arterioscler Thromb Vasc Biol (2016) 36(5):1003-9. doi:10.1161/ATVBAHA.115.306683

82. Forbang NI, Criqui MH, Alllion MA, Ix JH, Steffen BT, Cushman M, et al. Sex and ethnic differences in the associations between lipoprotein(a) and peripheral arterial disease in the Multi-Ethnic Study of Atherosclerosis. J Vasc Surg (2016) 63(2):453-8. doi:10.1016/j.jvs.2015.08.114

Conflict of Interest Statement: The authors declare that the research was conducted in the absence of any commercial or financial relationships that could be construed as a potential conflict of interest.

The reviewer LB and handling editor declared their shared affiliation, and the handling editor states that the process met the standards of a fair and objective review.

Copyright $\odot 2017$ Osei and Gaillard. This is an open-access article distributed under the terms of the Creative Commons Attribution License (CC BY). The use, distribution or reproduction in other forums is permitted, provided the original author(s) or licensor are credited and that the original publication in this journal is cited, in accordance with accepted academic practice. No use, distribution or reproduction is permitted which does not comply with these terms. 